\title{
Effect of enhanced recovery after surgery in the managements of ankle fracture patients: a single-center retrospective cohort study
}

\author{
Yuefeng Yao \\ Peking University Shenzhen Hospital \\ Guoqing Li \\ Peking University Shenzhen Hospital https://orcid.org/0000-0002-8956-5926 \\ Su Liu \\ Peking University Shenzhen Hospital \\ Ao Xiong \\ Peking University Shenzhen Hospital \\ Chang Xu \\ Peking University Shenzhen Hospital \\ Deli Wang \\ Peking University Shenzhen Hospital \\ Hui Zeng ( $\nabla$ zenghui_36@163.com ) \\ Peking University Shenzhen Hospital https://orcid.org/0000-0001-6966-0769
}

\section{Research}

Keywords: Enhanced Recovery After Surgery (ERAS), Ankle fracture, Length of stay (LOS), American Orthopaedic Foot and Ankle Society (AOFAS)

Posted Date: December 23rd, 2020

DOl: https://doi.org/10.21203/rs.3.rs-132422/v1

License: (1) (i) This work is licensed under a Creative Commons Attribution 4.0 International License. Read Full License 


\section{Abstract \\ Background}

Ankle fracture is common and the treatment is embarrassed. Enhanced Recovery After Surgery (ERAS) has been successfully adopted for the improvement of efficacy and quality. However, application of ERAS in ankle fracture patients especially at the early stage is variable and remains to be clarified. We intent to explore the effect of ERAS among ankle fracture patients.

\section{Methods}

There were 29 male and 51 female patients aged $41.71 \pm 14.51$ years who were consecutively grouped into non-ERAS group $(n=40)$ and ERAS group $(n=40)$. Univariate analysis and multiple linear regression analysis were applied to assess the association in outcomes and variables.

\section{Results}

AOFAS at post-operative 3 month (PO3M) and post-operative 6 month (PO6M), costs, length of stay (LOS), and pre-operative LOS were verified significantly in univariate analysis. Multiple linear regression analysis revealed that ERAS can improve American Orthopaedic Foot and Ankle Society (AOFAS) at PO3M ( $\beta=7.06,95 \% \mathrm{Cl}, 4.45-9.65)$ and PO6M $(\beta=5.08,95 \% \mathrm{Cl}, 2.35-7.80)$, reduce costs $(\beta=-6885.13,95 \% \mathrm{Cl},-12089.40--1680.85)$ and LOS $(\beta=-3.27,95 \% \mathrm{Cl},-4.97--1.57)$ among ankle fracture patients. With the

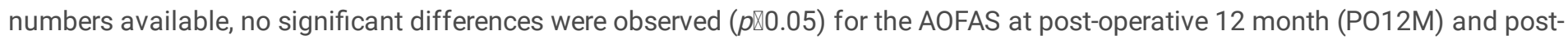
operative 24 month (PO24M), complications, or opioids consumption.

\section{Conclusion}

We found ERAS is superior to general protocol among proper ankle fracture patients, which can enhance rehabilitation especially at the early stage and improve medical quality and efficiency by reducing costs and LOS. ERAS protocol may have a promising future and worth promoting.

\section{Introduction}

The ankle joint is the largest weight-bearing joint in human body and the fracture is the most common intra-articular fracture [1]. The rate of ankle fracture increased with the development of aging society, sports activities, or even widely use of cell phones, which often causes a high disabled rate and increases the economic burden of the family and society [2,3]. The managements of ankle fracture at the time of operation remains one of the most challenging tasks for orthopedists because of special anatomic.

ERAS was firstly proposed by Kehlet, which can decrease complications, shorten the LOS, and improve patients' satisfaction [4]. ERAS has been successfully adopted across a range of diseases, which was performed well in the improvement of outcomes at the early stage $[5,6]$. There lacks high-quality literature investigating the managements of ankle fracture patients with the application of ERAS in the early post-operative stage. Diagnosis-related groups (DRGs) payment have a significant impact on the hospital market. The indicator LOS is used to gain insight into quality and safety of medical care, which is one of the most crucial manifestations of DRGs [7]. Patient socioeconomic status appears to be associated with LOS and costs, which suggests ankle fracture patients may require reform to improve quality and efficacy.

Previous study implies that ERAS application for trauma injury is effective but without standard process, moreover, the assumed advantages of ERAS for ankle fracture patients have not been sufficiently studied. Ankle fracture treatment may be complicated by postoperative pain, increased LOS, higher costs, and decreased patient satisfaction. Studies are needed to investigate effect of ERAS protocol on its short-term clinical outcomes, and therefore, we launched this study to explore the impact of the ERAS at the early stage in ankle fracture patients based on preliminary experience and evidence-based medicine (EBM).

\section{Methods}




\section{Patients}

The study was carried out in our hospital located in south of China between January and May in 2018. Patients who refuse to be admitted into the study, caught open fractures, with sever comorbidities, undergone previous surgery on the injured ankle, younger than 14-year old, loss of follow-up, or information missed were excluded. During the study period, 114 ankle fracture patients were treated and 34 cases were excluded, 6 cases for not meeting inclusion criteria, 9 cases for not giving consent, and 19 cases for loss of follow-up or information missed. We included ankle fracture patients who met inclusion and exclusion criteria (Fig. 1). All enrolled patients were invited for a clinical and radiological follow-up and the mean period was 24 months. All of the surgeries were conducted by the same experienced and skilled surgeon.

\section{Variables}

We reviewed discharged abstract that involved a multitude of variables and data was obtained from medical electronic records system retrospectively. Patient characteristics including age, gender, diagnosis, Lauge-Hansen (LH) classification, Danis-Weber (DW) classification, ankle joint dislocation or not, medial malleolar injury (fracture or ligment rupture), operative date, and comorbidities (hypertension; diabetes metabolism (DM); coronary heart disease (CHD), stroke, and others).

To confirm outcomes reported noted in the literatures, we identified patient-reported outcome measures (PROMs). The outcomes including AOFAS at P03M, P06M, P012M, and P024M. we also included costs, total LOS, pre-operative LOS, post-operative LOS, the occurrence of post-operative complications, and opioids consumption in the first 24-hour. LOS (in days) were defined as the number of days from admission to discharge. The investigation of the outcomes was performed carefully to ensure the validity of the study.

\section{Application of ERAS}

ERAS would take account into the patients' conditions and individual differences, which require the multi-disciplinary team (MDT) work. Our group developed the relevant pathway for patients according to the consensus guideline by means of improving the knowledge, popularizing the proper understanding effect, and standardizing the process (Fig. 2).

\section{Discharge criteria}

Previous studies emphasize the discharge criteria for ankle fracture patients varies worldwide [8]. The discharge criteria for ankle fracture patients in our department are the followings when clinically appropriate. (1) Patients who are willing to be discharged, (2) patient signs such as appetite and sleep are normal and stable, (3) incision heals well without any symptoms of infection, (4) hematological results are normal, (5) visual analogue scale (VAS) $\leq 3$.

\section{Statistics analysis}

Outcomes are respectively summarized by descriptive statistics. Continuous variables were summarized using mean \pm standard deviation (SD) while categorical variables were summarized using number and percentage. Univariate analysis was used to analyze the relationships of the variables and multiple linear regression analysis was performed to examine the effects of significant variables on the outcomes. Paired two-sided $t$ test if samples conformed to the normal distribution while Mann-Whitney U test for no normality of distribution of the continuous variables. We used the Chi-square test in cases with all expected values greater than five, otherwise we used the two-sided Fisher's exact test for category variables. All statistical analysis was performed on SPSS Statistics (IBM version 25.0) and $\mathrm{R}$ (version 4.0.2). $p<0.05$ were considered statistically significant and $p<0.001$ were considered statistically highly significant. We also reported $95 \%$ confidence interval $(C l)$ for each parameter estimate.

\section{Results}

The patients who were diagnosed ankle fracture underwent open reduction and internal fixation (ORIF) were consecutively grouped into the Non-ERAS $(n=40)$ and ERAS $(n=40)$ care pathway. 80 patients were ultimately included in the present study. There were 29 males and 51 females with an average of $41.71 \pm 14.51$ years. All participants were followed up around 24 months (22.6 months 27.2 months) and we evaluate patients' rehabilitation by AOFAS at P03M, P06M, P012M, and P024M. With the numbers available, no significant $(p>0.05)$ difference was observed among patient demographic variables (Table 1$)$. 
Table 1

Analysis of demographic characteristics for ankle fracture patients $(\mathrm{N}=80)$

\begin{tabular}{|c|c|c|c|c|c|c|}
\hline \multirow[t]{2}{*}{ Variables } & \multirow[t]{2}{*}{ Categories } & \multicolumn{2}{|c|}{ Non-ERAS $(\mathrm{N}=40)$} & \multicolumn{2}{|c|}{ ERAS $(\mathrm{N}=40)$} & \multirow[t]{2}{*}{$p$ value } \\
\hline & & Count & Description & Count & Description & \\
\hline \multirow[t]{4}{*}{ Age (years) } & Mean & \multirow[t]{4}{*}{40} & 41.63 & \multirow[t]{4}{*}{40} & 41.80 & \multirow[t]{4}{*}{0.957} \\
\hline & SD & & 14.21 & & 14.98 & \\
\hline & Media & & 40.50 & & 40.00 & \\
\hline & Min-max & & $14-67$ & & $14-71$ & \\
\hline \multirow[t]{2}{*}{ Gender } & Male & 14 & $65.00 \%$ & 15 & $27.50 \%$ & \multirow[t]{2}{*}{0.816} \\
\hline & Female & 26 & $35.00 \%$ & 25 & $62.50 \%$ & \\
\hline \multirow{4}{*}{$\begin{array}{l}\text { LH } \\
\text { classification }\end{array}$} & SA & 2 & $5.00 \%$ & 4 & $10.00 \%$ & \multirow[t]{4}{*}{$0.887^{a}$} \\
\hline & SER & 25 & $62.50 \%$ & 24 & $60.00 \%$ & \\
\hline & PER & 12 & $30.00 \%$ & 11 & $27.50 \%$ & \\
\hline & PA & 1 & $2.50 \%$ & 1 & $2.50 \%$ & \\
\hline \multirow{3}{*}{$\begin{array}{l}\text { DW } \\
\text { classification }\end{array}$} & $A$ & 3 & $7.50 \%$ & 3 & $7.50 \%$ & \multirow[t]{3}{*}{$0.781^{a}$} \\
\hline & B & 24 & $60.00 \%$ & 25 & $62.50 \%$ & \\
\hline & $\mathrm{C}$ & 13 & $32.50 \%$ & 12 & $30.00 \%$ & \\
\hline \multirow[t]{2}{*}{ Dislocation } & No & 29 & $72.50 \%$ & 24 & $60.00 \%$ & \multirow[t]{2}{*}{$0.237^{b}$} \\
\hline & Yes & 11 & $27.50 \%$ & 16 & $40.00 \%$ & \\
\hline \multirow{3}{*}{$\begin{array}{l}\text { Medial malleolar } \\
\text { injury }\end{array}$} & No & 10 & $25.00 \%$ & 17 & $42.50 \%$ & \multirow[t]{3}{*}{$0.169^{a}$} \\
\hline & Ligament & 13 & $32.50 \%$ & 7 & $17.50 \%$ & \\
\hline & Bone & 17 & $42.50 \%$ & 16 & $40.00 \%$ & \\
\hline \multirow[t]{5}{*}{ Comorbidities } & No & 32 & $80.00 \%$ & 37 & $92.50 \%$ & \multirow[t]{5}{*}{$0.449^{a}$} \\
\hline & Hypertension & 2 & $5.00 \%$ & 0 & $0.00 \%$ & \\
\hline & DM & 3 & $7.50 \%$ & 2 & $5.00 \%$ & \\
\hline & $\mathrm{CHD}$ & 1 & $2.50 \%$ & 0 & $0.00 \%$ & \\
\hline & Others & 2 & $5.00 \%$ & 1 & $2.50 \%$ & \\
\hline \multicolumn{7}{|c|}{${ }^{a}$ Fisher's Exact Test, ${ }^{b}$ Pearson's Chi-squared test. } \\
\hline \multicolumn{7}{|c|}{$\begin{array}{l}\text { Abbreviations: ERAS, Enhanced Recovery After Surgery; SD, standard deviation; LH, Lauge-Hansen; supination-adduction, SA; } \\
\text { supination-external rotation, SER; pronation-external rotation, PER; pronation-abduction, PA; DW, Denis-Weber; DM, diabetes } \\
\text { metabolism; CHD, coronary heart disease. }\end{array}$} \\
\hline
\end{tabular}

Some of the outcomes including different point AOFAS were reflected in the form of curves in Fig. 3. Outcomes of LOS and costs and ERAS were reflected in the form of curves in Fig. 4.

Univariate analysis reveals that significant difference outcomes in PO3M AOFAS (95\% Cl, -9.018 to -4.132$)$, PO6M AOFAS (95\% Cl, -7.137 to -2.013$)$, costs $(95 \% \mathrm{Cl}, 735.351$ to 13831.559$)$, LOS ( $95 \% \mathrm{Cl}, 1.644$ to 4.956$)$, and pre-operative LOS (95\% Cl, 0.896 to 3.404 ) were verified between the two groups $(p<0.05)$. With the numbers available, no significant differences were observed for P012M 
AOFAS ( $95 \% \mathrm{Cl},-0.931$ to 0.682$)$, PO24M AOFAS ( $95 \% \mathrm{Cl},-1.132$ to 0.332$)$, complications, and opioids consumption between the two groups $(p>0.05)$ (Table 2$)$.

Table 2

Univariate analysis of outcomes between the two groups $(\mathrm{N}=80)$

\begin{tabular}{|c|c|c|c|c|c|c|c|c|c|}
\hline \multirow[t]{2}{*}{ Outcomes } & \multicolumn{2}{|c|}{ Non-ERAS } & \multicolumn{2}{|l|}{ ERAS } & \multirow{2}{*}{$\begin{array}{l}F / \\
\text { OR }\end{array}$} & \multirow[t]{2}{*}{ S.E } & \multirow[t]{2}{*}{$t / \chi 2$} & \multirow[t]{2}{*}{$P$ value } & \multirow[t]{2}{*}{$95 \% \mathrm{Cl}$} \\
\hline & Count & Description & Count & Description & & & & & \\
\hline P03M AOFAS & 40 & $\begin{array}{l}76.17 \pm \\
5.91\end{array}$ & 40 & $\begin{array}{l}82.75 \pm \\
5.04\end{array}$ & 0.090 & 1.227 & -5.357 & $0.000 * \star$ & {$[-9.018,-4.132]$} \\
\hline P06M AOFAS & 40 & $\begin{array}{l}85.28 \pm \\
6.21\end{array}$ & 40 & $\begin{array}{l}89.85 \pm \\
5.26\end{array}$ & 0.369 & 1.287 & -3.555 & $0.001 *$ & {$[-7.137,-2.013]$} \\
\hline $\begin{array}{l}\text { P012M } \\
\text { AOFAS }\end{array}$ & 40 & $\begin{array}{l}93.02 \pm \\
2.02\end{array}$ & 40 & $\begin{array}{l}93.15 \pm \\
1.58\end{array}$ & 1.238 & 0.405 & -0.309 & 0.806 & {$[-0.931,0.682]$} \\
\hline $\begin{array}{l}\text { PO24M } \\
\text { AOFAS }\end{array}$ & 40 & $\begin{array}{l}96.45 \pm \\
1.96\end{array}$ & 40 & $\begin{array}{l}96.85 \pm \\
1.25\end{array}$ & 3.351 & 0.368 & -1.088 & 0.280 & {$[-1.132,0.332]$} \\
\hline Costs & 40 & $\begin{array}{l}43827.82 \\
\pm 13669.16\end{array}$ & 40 & $\begin{array}{l}36544.36 \\
\pm 15680.64\end{array}$ & 0.259 & 3289.104 & 2.214 & $0.030 *$ & {$[735.351,13831.559]$} \\
\hline Total LOS & 40 & $\begin{array}{l}13.20 \pm \\
3.95\end{array}$ & 40 & $9.90 \pm 3.48$ & 0.063 & 0.832 & 3.966 & $0.000 * \star$ & {$[1.644,4.956]$} \\
\hline Pre-op LOS & 40 & $5.65 \pm 3.52$ & 40 & $3.50 \pm 1.87$ & 9.125 & 0.630 & 3.413 & $0.001 *$ & {$[0.896,3.404]$} \\
\hline Post-op LOS & 40 & $7.55 \pm 3.27$ & 40 & $6.40 \pm 2.70$ & 0.125 & 0.670 & 1.717 & 0.113 & {$[-0.183,2.483]$} \\
\hline \multirow[t]{2}{*}{ Complications } & No & 38 (95\%) & No & $\begin{array}{l}40 \\
(100.00 \%)\end{array}$ & \multirow[t]{2}{*}{0.950} & \multirow[t]{2}{*}{-} & \multirow[t]{2}{*}{2.051} & \multirow[t]{2}{*}{$0.493^{a}$} & \multirow[t]{2}{*}[0.885,1.020]{} \\
\hline & Yes & $2(5 \%)$ & Yes & $0(0.00 \%)$ & & & & & \\
\hline \multirow{2}{*}{$\begin{array}{l}\text { Post-op } \\
\text { Opioids } \\
\text { consumption }\end{array}$} & No & $\begin{array}{l}27 \\
(67.50 \%)\end{array}$ & No & $\begin{array}{l}31 \\
(77.50 \%)\end{array}$ & \multirow[t]{2}{*}{0.603} & \multirow[t]{2}{*}{-} & \multirow[t]{2}{*}{1.003} & \multirow[t]{2}{*}{$0.317^{b}$} & \multirow[t]{2}{*}[0.223,1.630]{} \\
\hline & Yes & $\begin{array}{l}13 \\
(32.50 \%)\end{array}$ & Yes & $9(22.50 \%)$ & & & & & \\
\hline \multicolumn{10}{|c|}{$\begin{array}{l}{ }^{\star *} \text {, Correlation is significant at the } 0.01 \text { level (2-taile } \\
{ }^{\text {a }} \text { Fisher's Exact Test, }{ }^{b} \text { Pearson's Chi-squared test. }\end{array}$} \\
\hline \multicolumn{10}{|c|}{$\begin{array}{l}\text { Abbreviations: ERAS, Enhanced Recovery After Surgery; S.E, standard error; Cl, confidence interval; PO3M, post-operative } 3 \\
\text { months; AOFAS, American Orthopaedic Foot and Ankle Society; PO6M, post-operative } 6 \text { months; PO12M, post-operative } 12 \\
\text { months; PO24M, post-operative } 24 \text { months; Pre-op, pre-operative; LOS, length of stay; Post-op, post-operative. }\end{array}$} \\
\hline
\end{tabular}

Multiple linear regression analysis reveals that P03M AOFAS $(\beta=7.06,95 \% \mathrm{Cl}, 4.45-9.65)$, PO6M AOFAS $(\beta=5.08,95 \% \mathrm{Cl}, 2.35-$ 7.80), LOS $(\beta=-3.27,95 \% \mathrm{Cl},-4.97--1.57)$, and costs $(\beta=-6885.13,95 \% \mathrm{Cl},-12089.40-1680.85)$ are significantly associated with ERAS $(p<0.05)$. ERAS can improve AOFAS and reduce costs and LOS among ankle fracture patients (Table 3 ). 
Table 3

Multiple linear regression analysis of outcomes between the two groups $(\mathrm{N}=80)$

\begin{tabular}{|c|c|c|c|c|c|c|}
\hline \multirow[t]{3}{*}{ Outcomes } & \multicolumn{6}{|l|}{ Group } \\
\hline & \multirow{2}{*}{$\begin{array}{l}\text { Non-ERAS } \\
\text { (Reference) }\end{array}$} & \multicolumn{5}{|l|}{ ERAS } \\
\hline & & $\beta$ & S.E & t value & $\mathrm{p}$ value & $95 \% \mathrm{Cl}$ \\
\hline PO3M AOFAS & - & 7.06 & 1.3 & 5.42 & $<0.001^{\star \star}$ & {$[4.45-9.65]$} \\
\hline P06M AOFAS & - & 5.08 & 1.36 & 3.72 & $<0.001^{\star \star}$ & {$[2.35-7.80]$} \\
\hline P012M AOFAS & - & 0.09 & 0.43 & 0.22 & 0.823 & {$[-0.76-0.95]$} \\
\hline P024M AOFAS & - & 0.29 & 0.39 & 0.74 & 0.459 & {$[-0.49-1.08]$} \\
\hline Total LOS & - & -3.27 & 0.85 & -3.84 & $<0.001 \star \star$ & [-4.97- - -1.57] \\
\hline Costs & - & -6885.13 & 2606.6 & -2.64 & $0.010^{*}$ & {$[-12089.40--1680.85]$} \\
\hline \multicolumn{7}{|c|}{ **, Correlation is significant at the 0.01 level (2-tailed), *, Correlation is significant at the 0.05 level (2-tailed). } \\
\hline \multicolumn{7}{|c|}{$\begin{array}{l}\text { Footnotes: Abbreviations: ERAS, Enhanced Recovery After Surgery; S.E, standard error; Cl, confidence interval; PO3M, post- } \\
\text { operative } 3 \text { months; AOFAS, American Orthopaedic Foot and Ankle Society; PO6M, post-operative } 6 \text { months; PO12M, post- } \\
\text { operative } 12 \text { months; PO24M, post-operative } 24 \text { months; LOS, length of stay. }\end{array}$} \\
\hline
\end{tabular}

\section{Discussion}

Represented in the medical literature, Ankle fractures are one of the most common skeletal injuries and accounting for approximately $7-10 \%$ of emergency department (ED) visits [9]. Traumatic injury of the ankle constitute almost $40 \%$ of all sports injuries, which can result in long-term disability and cause substantial negative implication on patient's functional recovery [10]. The appropriate diagnosis and managements of the challenging injuries still remains controversial. Moreover, rapid and large-scale implementation of ERAS program is feasible and effective [11]. Patient-center approach to optimize patients care and experience during the perioperative period, which has been shown to be effective in improving outcomes $[12,13]$.

Present studies confirmed that standardized ERAS protocols can optimize the outcome of ankle fracture patients. As the major principle of treatment remains to achieve an anatomic reduction and a stable fixation, precise preoperative diagnostics and treatment planning are of great importance. Available literature revealed that combined injuries are common among ankle fracture patients which can result in significant adverse effect. Stenquist et al suggest that patients with any medial tenderness were at significantly higher risk of unstable ankle fracture with instability [14]. Casting or orthosis application non-inferior to cast immobilization is recommended for stable ankle fractures [15-18]. Naumann et al suggested that 6 days would be a safe window for operation that can be used to plan and perform the final operation [19]. While ORIF is an optional strategy for unstable ankle fractures, syndesmosis and deltoid ligament repair may promote fracture union and allows patients to start earlier weight-bearing [20, 21]. Some of the patients accompanied with several combined injuries or dislocation, fortunately, all of them were treated properly and gain satisfied outcomes of rehabilitation.

AOFAS is a powerful tool to evaluate ankle disorders' function and rehabilitation [22]. We evaluated PROMs by AOFAS at different point after operation at P03M, P06M, P012M, and P024M. Significant difference of outcomes at PO3M and P06M were verified. With the numbers available, no significant differences were observed $(p>0.05)$ at P012M and P024M were verified between the two groups. However, we notice that better prognosis and tendency in ERAS group in the P012M. Orthopedic surgeons and rehabilitation physicians often in conjunction together to manage patients with fractures [23]. Some of the researchers believed that special designed devices shown advantages to reduce adverse events and accelerate rehabilitation [24, 25]. One of the significant methods in ERAS is to make proper procedure that including reduction and temporary fixation under emergency anesthesia after the careful evaluation in ED. Patients would obtain early mobility and pain relief through the perioperative management, which is good for accelerate rehabilitation. Multiple linear regression analysis reveals that PO3M and P06M AOFAS were verified between the two groups $(p<0.05)$. ERAS protocol can improve the outcomes in terms of short-term rehabilitation and we believe that patients will have favorable outcomes when treated by all of these subspecialty providers. 
Previous analysis demonstrated that demographic characteristics and procedures may affect the coats and LOS of ankle fracture patients, which has important clinical and economic implications, providing a target for improving patient outcomes [26, 27]. Significant different outcomes were verified $(p<0.05)$ including costs and LOS are associated with ERAS in both univariate analysis and multiple linear regression analysis, which are in line with previous study and confirm the advantages of the ERAS. The finding application of ERAS can reduce the costs and LOS may assist staff and patients pay more attention to the application of ERAS during clinical practice. DRGs payment system was introduced and mandated worldwide for its potential to curbing unnecessary resource and cost-saving implications by decreasing costs and LOS [28, 29]. Relevant literatures reflected that healthcare system assess satisfaction and quality of the inpatients, which highlights the specification of ERAS [30,31]. Efforts to improve the healthcare should be focused on implementation and enlargement of the DRGs and ERAS.

Traumatic injuries are particularly challenging when they associate skin and soft tissue frail. Perioperative complications are challenges and unsolved problems, underlining the need for further research. In view of frequent recommendations and reports, ERAS protocol has been applicated for many diseases without increasing rate of adverse outcomes [32, 33]. Among all of the patients, no complication was observed in ERAS group. No case caught complication in ERAS group. Two cases in non-ERAS group developed into superficial incision infection and urinary tract infection but were cured with proper procedure. The characteristic of the old, comorbidity, and obesity are more likely to caught complications [34, 35]. Benefit of ERAS application prevent complication is not statistic significant but there exists a tendency in univariate analysis (OR: 0.950, $p>0.05,95 \% \mathrm{Cl}, 0.885$ to 1.020 ), which may be limited for small sample.

Ankle fracture can cause post-operative pain but literature is scarce in evaluating opioids consumption in the first 24-hour. Previous study suggested that patients with opioid-related adverse events have greater higher risk of costs and ED visits [36, 37]. By understanding the impact of potential side effect of opioids, we intend to introduce perioperative pain managements but more evidence is needed to demonstrate during clinical practice. Patients would be evaluated after surgery and opioids will be prescribed if VAS $\geq 6$. The overall consumption of opioids are similar between two groups in univariate analysis (OR: $0.603, p>0.05,95 \% \mathrm{Cl}, 0.223$ to1.630). Moreover, we notice that the number of patients is smaller in ERAS group. Multi-modal analgesia strategies were adopted in ERAS group which may help to improve positive outcomes with better experience and satisfaction. With the direction of ERAS in perioperative plan, we believe ankle fracture patients would benefit more.

Our study has some strengths. To our knowledge, it is the first investigation to confirm the advantages of EARS application among the proper ankle fracture patients at different point after operation. The comprehensive data allowed us to examine the benefits of the ERAS protocol which can improve rehabilitation, quality and efficiency at the early stage. Furthermore, some limitations of the present study should be addressed before making a conclusion. First, the investigation was a retrospective cohort study which is associated with inherent selection bias. Second, we conducted the study with a single-center small database, multiply center giant samples and prospective protocols are needed for further study. Third, the standard of discharge may not be in consistent, which require standard discharge criteria among hospitals. Last but not least, the database did not include information on long-term follow-up outcomes. We believe that prospective studies with long-term follow-up are essential to define the machination clearly and more robust experimental designs are needed to validate the conclusions over time.

\section{Conclusion}

To make a conclusion, our study explores and illustrates the effect of ERAS can enhance the short-term rehabilitation especially at the early stage. We found ERAS can also improve quality and efficiency of health care by reducing costs and LOS among proper ankle fracture patients. ERAS has a promising future and worth promoting.

\section{Abbreviations}

Enhanced Recovery After Surgery, ERAS; post-operative 3 month, P03M; post-operative 6 month, P06M; length of stay, LOS; American Orthopaedic Foot and Ankle Society, AOFAS; post-operative 12 month, P012M; post-operative 24 month, PO24M; Diagnosis-related groups, DRGs; evidence-based medicine, EBM; Lauge-Hansen, LH; Danis-Weber, DW; diabetes metabolism, DM; coronary heart disease, CHD; patient-reported outcome measures, PROMs; multi-disciplinary team, MDT; visual analogue scale, VAS; standard deviation, SD; confidence interval, $\mathrm{Cl}$; open reduction and internal fixation, ORIF; emergency department, ED. 


\section{Declarations}

\section{Ethics approval and consent to participate}

The research was conducted retrospectively, we have obtained participants' verbal consent and ethics approval from ethics committee. Ethical review approval was obtained from the Human Subject Committee and Ethics Committee (Ethics Committee of Peking University Shenzhen Hospital (research) (2018) 018th).

\section{Consent for publication}

Not applicable.

\section{Availability of data and materials}

Please contact the author for data requests.

\section{Competing interests}

All of the authors of this paper have disclosed potential or pertinent conflicts of interest, which may include receipt of payment, either direct or indirect, institutional support, or association with an entity in the biomedical field which may be perceived to have potential conflict of interest with this work. No conflicts reported in regards to this manuscript.

\section{Funding}

This study was supported by grants from Shenzhen Key Medical Subject (No. SZXK023), Shenzhen "San-Ming" Project of Medicine (No. SZSM201612092), Guangdong Basic and Applied Basic Research Foundation (No. 2019A1515011290), Shenzhen Research and Development Projects (No. JCYJ20170307111755218), Shenzhen Research and Development Projects (No. JCYJ20190809110807421), Scientific research project of health and family planning system in Shenzhen (No. SZXJ2018077), The basic research project of Peking University Shenzhen Hospital (No. JCYJ2018004).

\section{Author's contribution}

Yuefeng Yao and Guoqing Li participated in the design and prepared the manuscript. Yuefeng Yao and Guoqing Li contribute equally to this work and they are listed as cooperated first authors. Ao Xiong and Su Liu participated in the critical revision of the manuscript; Chang Xu participated in execution and analysis of the work presented. Deli Wang and Hui Zeng participated in the design, participated in the critical revision of the manuscript, and reviewed the final manuscript. Deli Wang and Hui Zeng contribute equally to this work and they are listed as corresponding authors.

\section{Acknowledgements}

The authors sincerely acknowledge the entire staff of the Department of Bone \& Joint Surgery, Peking University Shenzhen Hospital, who offered their assistance throughout the course of this study.

\section{References}

1. Sim, J., N. Grocott, H. Majeed, and D. McClelland, Effect on Hospital Length of Stay of Tourniquet Use During Internal Fixation of Ankle Fractures: Randomized Controlled Trial. J Foot Ankle Surg, 2019. 58(1): p. 114-118.

2. Moore, H.G., S.J. Halperin, E.R. Berson, P.J. Burroughs, B. Paskhover, and J.N. Grauer, Orthopaedic Injuries Associated With Cell Phone Use Resulting in Emergency Department Visits: A 20-year Analysis. J Am Acad Orthop Surg, 2020.

3. Thiebat, G., A. Spreafico, S. Mazzoni, G. Ravasio, L. De Girolamo, and H. Schoenhuber, Incidence of injuries in young soccer players: epidemiological study in an Italian elite club. J Sports Med Phys Fitness, 2020.

4. Wilmore, D.W. and H. Kehlet, Management of patients in fast track surgery. Bmj, 2001. 322(7284): p. 473-6.

5. Yin, M., Y. Yan, Z. Fan, N. Fang, H. Wan, W. Mo, and X. Wu, The efficacy of Enhanced Recovery after Surgery (ERAS) for elderly patients with intertrochanteric fractures who received surgery: study protocol for a randomized, blinded, controlled trial. J Orthop Surg Res, 2020. 15(1): p. 91. 
6. Edwards, P.K., J.R. Kee, S.C. Mears, and C.L. Barnes, Is Rapid Recovery Hip and Knee Replacement Possible and Safe in the Octogenarian Patient? J Arthroplasty, 2018. 33(2): p. 316-319.

7. Michel, M., C. Alberti, J.C. Carel, and K. Chevreul, Association of Pediatric Inpatient Socioeconomic Status With Hospital Efficiency and Financial Balance. JAMA Netw Open, 2019. 2(10): p. e1913656.

8. Marsh, J., L. Somerville, J.L. Howard, and B.A. Lanting, Significant cost savings and similar patient outcomes associated with early discharge following total knee arthroplasty. Can J Surg, 2019. 62(1): p. 20-24.

9. Le, M.Q.T. and T.K. Tiu, Calcaneofibular Ligament Injury, in StatPearls. 2020, StatPearls Publishing Copyright @ 2020, StatPearls Publishing LLC.: Treasure Island (FL).

10. Taghavi, C.E., M.I. Sandlin, and D.B. Thordarson, Challenges and Controversies of Foot and Ankle Trauma. Instr Course Lect, 2017. 66: p. 25-37.

11. Liu, V.X., E. Rosas, J. Hwang, E. Cain, A. Foss-Durant, M. Clopp, M. Huang, D.C. Lee, A. Mustille, P. Kipnis, and S. Parodi, Enhanced Recovery After Surgery Program Implementation in 2 Surgical Populations in an Integrated Health Care Delivery System. JAMA Surg, 2017. 152(7): p. e171032.

12. Jones, D.B., M.R.A. Abu-Nuwar, C.M. Ku, L.S. Berk, L.S. Trainor, and S.B. Jones, Less pain and earlier discharge after implementation of a multidisciplinary enhanced recovery after surgery (ERAS) protocol for laparoscopic sleeve gastrectomy. Surg Endosc, 2020.

13. Noba, L., S. Rodgers, C. Chandler, A. Balfour, D. Hariharan, and V.S. Yip, Enhanced Recovery After Surgery (ERAS) Reduces Hospital Costs and Improve Clinical Outcomes in Liver Surgery: a Systematic Review and Meta-Analysis. J Gastrointest Surg, 2020. 24(4): p. 918-932.

14. Stenquist, D.S., C. Miller, B. Velasco, P. Cronin, and J.Y. Kwon, Medial tenderness revisited: Is medial ankle tenderness predictive of instability in isolated lateral malleolus fractures? Injury, 2020.

15. Golby, R. and A. Kestler, For stable Weber B ankle fractures, is three weeks of casting or orthosis application non-inferior to six weeks of cast immobilization? Cjem, 2020: p. 1-3.

16. Dryden, P., M. Halai, and R. Buckley, Midshaft fibula fracture with an unstable ankle injury: Plate the fibula and repair the syndesmosis or repair the syndesmosis alone. Injury, 2020. 51(3): p. 590-591.

17. von Keudell, A.G., T.K. Rajab, M.S. Vrahas, E.K. Rodriguez, M.B. Harris, and M.J. Weaver, Closed Reduction of a Fractured and Dislocated Ankle. N Engl J Med, 2019. 381(12): p. e25.

18. Piyapittayanun, P., K. Mutthakalin, A. Arirachakaran, and J. Kongtharvonskul, Comparative outcomes of foot cast and short leg cast in pseudo-Jones avulsion fracture: a single blinded randomized controlled trial. J Foot Ankle Res, 2019.12 : p. 47.

19. Naumann, M.G., U. Sigurdsen, S.E. Utvåg, and K. Stavem, Associations of timing of surgery with postoperative length of stay, complications, and functional outcomes 3-6 years after operative fixation of closed ankle fractures. Injury, 2017. 48(7): p. 16621669.

20. Li, B., S. Wang, Z. Zhang, H. Yang, J. Li, Q. Li, and L. Liu, Transarticular external fixation versus deltoid ligament repair in treating SER IV ankle fractures: a comparative study. BMC Musculoskelet Disord, 2019. 20(1): p. 453.

21. Morasiewicz, P., M. Dejnek, M. Kulej, S.L. Dragan, G. Konieczny, A. Krawczyk, W. Urbanski, W. Orzechowski, S.F. Dragan, and L. Pawik, Sport and physical activity after ankle arthrodesis with Ilizarov fixation and internal fixation. Adv Clin Exp Med, 2019. 28(5): p. 609-614.

22. Erichsen, J., L. Froberg, B. Viberg, F. Damborg, and C. Jensen, Danish Language Version of the American Orthopedic Foot and Ankle Society Ankle-Hindfoot Scale (AOFAS-AHS) in Patients with Ankle-Related Fractures. J Foot Ankle Surg, 2020. 59(4): p. 657663.

23. Sweeney, E.A., D.R. Howell, M.N. Potter, A.G. Gagliardi, J.C. Albright, and A.J. Provance, Comparison of pediatric sports fracture outcomes based on provider type. Phys Sportsmed, 2020: p. 1-6.

24. Clarkson, R., S.S.S. Mahmoud, A. Rangan, W. Eardley, and P. Baker, The use of foot pumps compression devices in the perioperative management of ankle fractures: Systematic review of the current literature. Foot (Edinb), 2017. 31: p. 61-66.

25. Zeng, L., Y. Wang, D. He, Y. He, Y. Wang, and X. Wei, The effectiveness of a self-made modular elastic compression device for patients with a fracture of the tibia and fibula. J Orthop Surg Res, 2020. 15(1): p. 153. 
26. Smeets, B., S. Nijs, M. Nderlita, C. Vandoren, and H. Hoekstra, Health Care Usage and Related Costs in Fibular Plating for AO Type 44-B Ankle Fractures in a Belgian University Hospital: An Exploratory Analysis. J Foot Ankle Surg, 2016. 55(3): p. 535-41.

27. Ghielen, J., S. Cihangir, K. Hekkert, I. Borghans, and R.B. Kool, Can differences in length of stay between Dutch university hospitals and other hospitals be explained by patient characteristics? A cross-sectional study. BMJ Open, 2019. 9(2): p. e021851.

28. Choi, J.W., S.J. Kim, H.K. Park, S.I. Jang, T.H. Kim, and E.C. Park, Effects of a mandatory DRG payment system in South Korea: Analysis of multi-year nationwide hospital claims data. BMC Health Serv Res, 2019. 19(1): p. 776.

29. Meng, Z., W. Hui, Y. Cai, J. Liu, and H. Wu, The effects of DRGs-based payment compared with cost-based payment on inpatient healthcare utilization: A systematic review and meta-analysis. Health Policy, 2020. 124(4): p. 359-367.

30. Ashton, F., K. Hamid, S. Sulieman, W. Eardley, and P. Baker, Factors Influencing patient experience and satisfaction following surgical management of ankle fractures. Injury, 2017. 48(4): p. 960-965.

31. Gellhorn, A.C., J.M. Stumph, H.E. Zikry, C.A. Creelman, and R. Welbel, Ultrasound measures of muscle thickness may be superior to strength testing in adults with knee osteoarthritis: a cross-sectional study. BMC Musculoskelet Disord, 2018. 19(1): p. 350.

32. Smith, G.A., S. Chirieleison, J. Levin, K. Atli, R. Winkelman, J.E. Tanenbaum, T. Mroz, and M. Steinmetz, Impact of length of stay on HCAHPS scores following lumbar spine surgery. J Neurosurg Spine, 2019. 31(3): p. 366-371.

33. Li, G., J. Weng, C. Xu, D. Wang, A. Xiong, and H. Zeng, Factors associated with the length of stay in total knee arthroplasty patients with the enhanced recovery after surgery model. J Orthop Surg Res, 2019. 14(1): p. 343.

34. Tomé-Bermejo, F., A. Santacruz Arévalo, and N. Ruiz Micó, [Open reduction and internal fixation of displaced ankle fractures in patients older than 65 years of age. Analysis of results at five-year follow-up]. Rev Esp Cir Ortop Traumatol, 2016. 60(2): p. 99105.

35. Li, N.Y., S. Kalagara, A. Hersey, A.E.M. Eltorai, A.H. Daniels, and A.I. Cruz, Jr., Impact of obesity on operative treatment and inpatient outcomes of paediatric limb fractures. Bone Joint J, 2019. 101-b(4): p. 491-496.

36. Allen, M.K., J.M. Parrish, R. Vakharia, J.R.M. Kaplan, E. Vulcano, M.W. Roche, and A.A. Aiyer, The Influence of Opioid Use Disorder on Open Reduction and Internal Fixation Following Ankle Fracture. Foot Ankle Spec, 2020: p. 1938640020914715.

37. Homsi, J., E.Y. Brovman, N. Rao, E.E. Whang, and R.D. Urman, The Association Between Potential Opioid-Related Adverse Drug Events and Outcomes in Colorectal Surgery. J Laparoendosc Adv Surg Tech A, 2019. 29(11): p. 1436-1445.

\section{Figures}




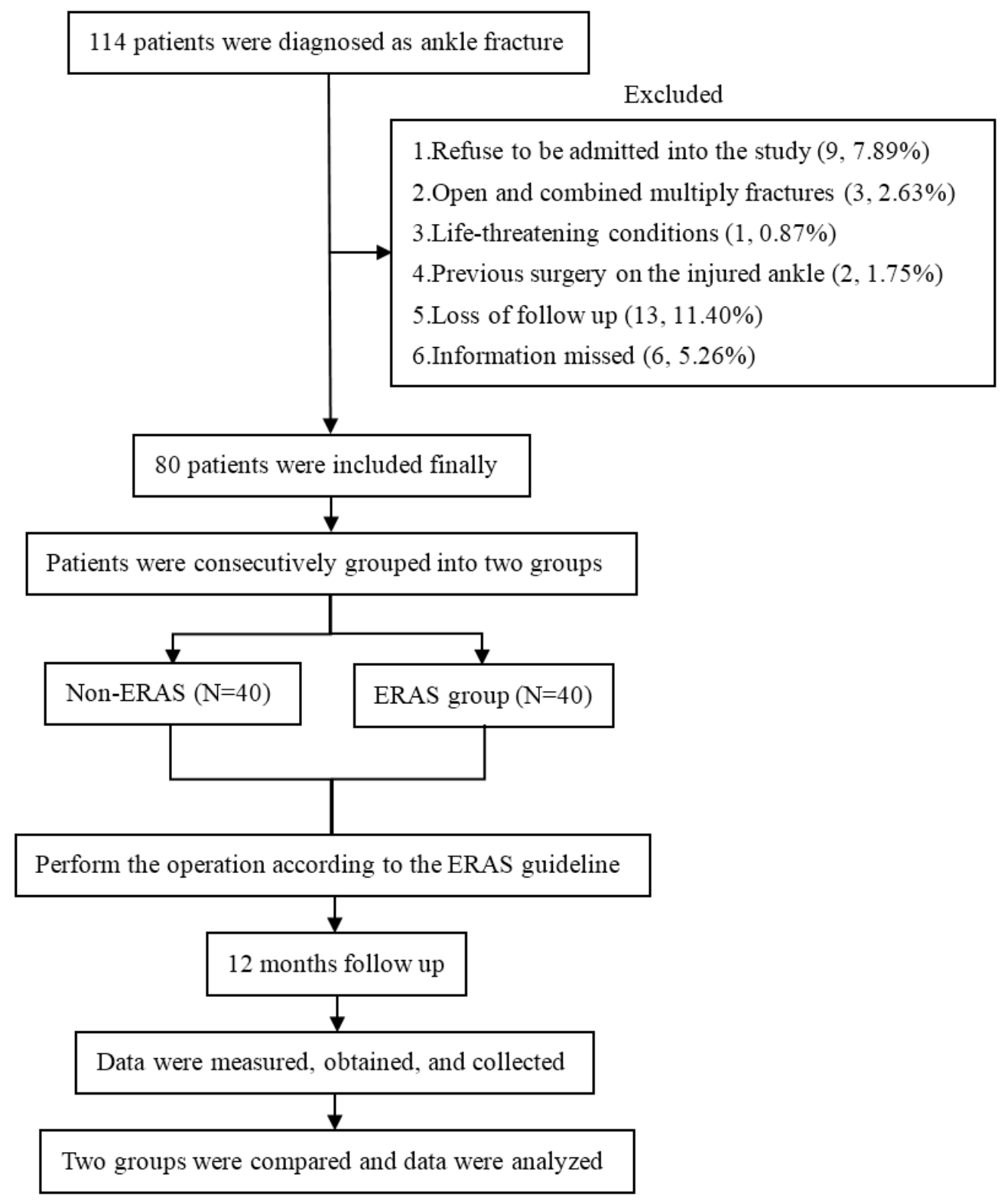

\section{Figure 1}

Flowchart that illustrates patient inclusion and exclusion 
Patient who were diagnosed ankle fracture

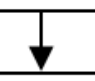

Physician evaluate the patients in ED

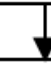

MDT: surgeons, anesthesiologists, internal physicians, rehabilitation physicians, nurses, and nutritionists

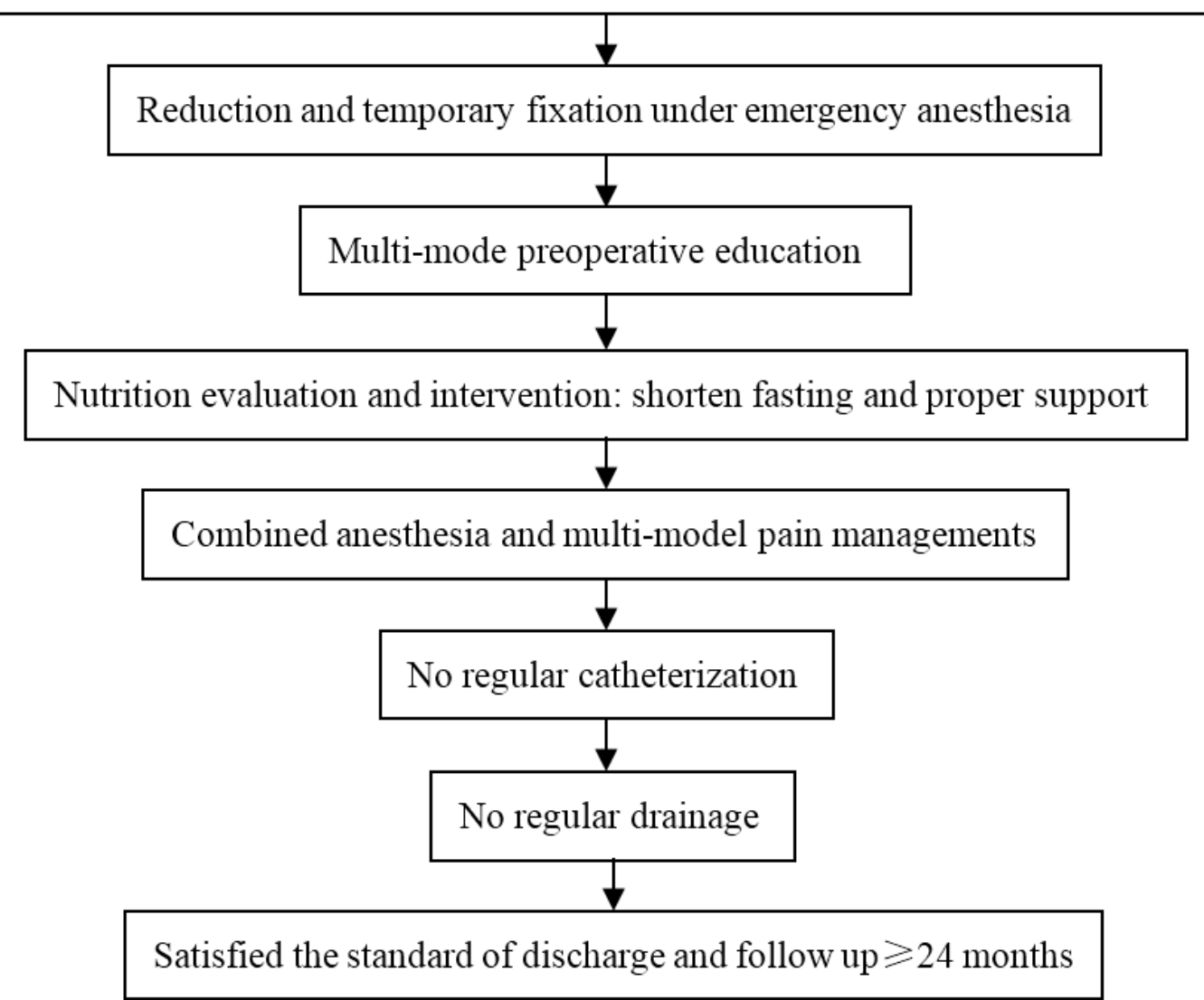

Figure 2

ERAS pathway for ankle fracture patients 

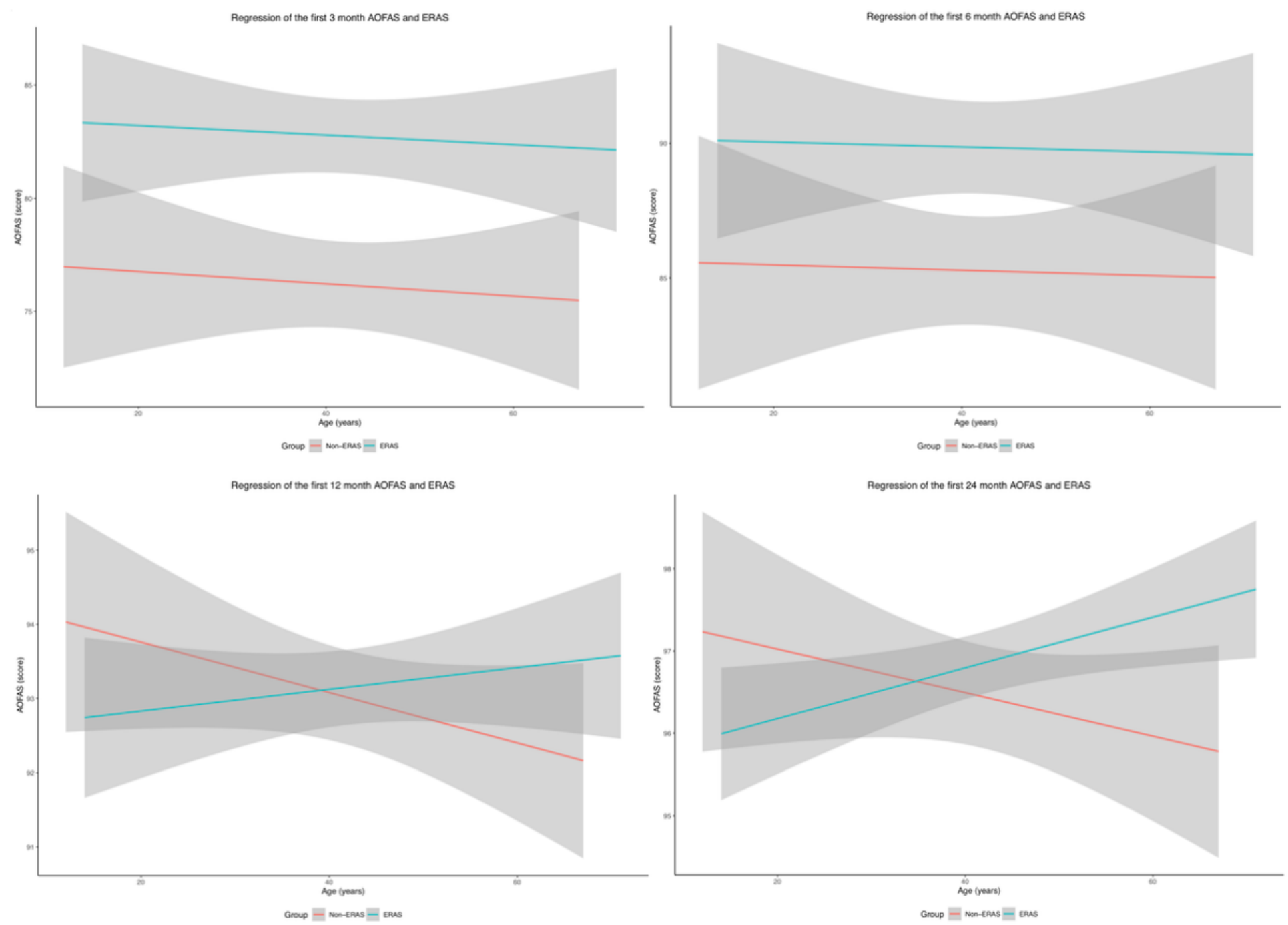

Figure 3

Regression curves of post-operative AOFAS between two groups
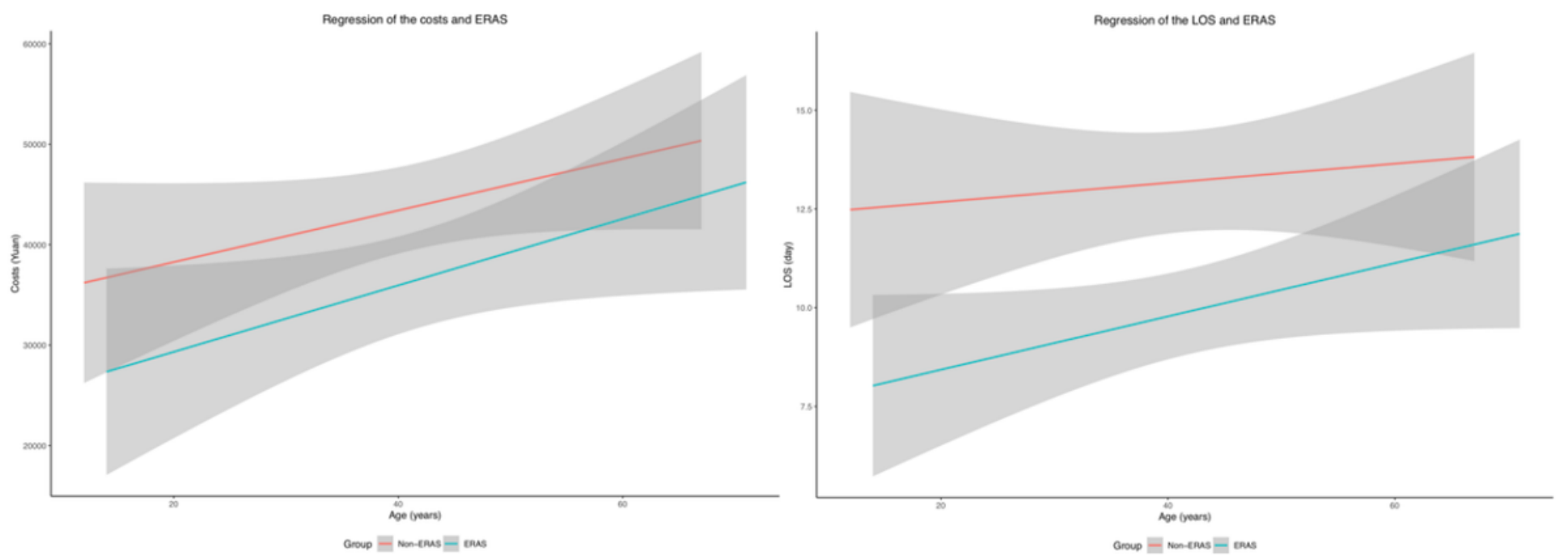

\section{Figure 4}

Regression curves of LOS and costs between two groups 